\title{
Quantification of $N$-phenyl-2-naphthylamine by gas chromatography and isotope-dilution mass spectrometry and its percutaneous absorption ex vivo under workplace conditions
}

\author{
Eike Maximilian Marek ${ }^{1} \cdot$ Stephan Koslitz $^{1} \cdot$ Tobias Weiss $^{1} \cdot$ Manigé Fartasch $^{1}$. \\ Gerhard Schlüter $^{1} \cdot$ Heiko Udo Käfferlein ${ }^{1}$ ' Thomas Brüning ${ }^{1}$
}

Received: 21 August 2017 / Accepted: 28 August 2017 / Published online: 12 September 2017

(c) The Author(s) 2017. This article is an open access publication

\begin{abstract}
N$-Phenyl-2-naphthylamine (P2NA) is an antioxidant used to protect rubbers from flex-cracking. P2NA can be converted in vivo to $2 \mathrm{NA}$, one of the most potent bladder carcinogens. Here, we report the specific and ultrasensitive quantification of P2NA in the receptor fluid of Franz diffusion cells by gas chromatography and isotopedilution tandem-mass spectroscopy (GC-MS/MS). The experimental conditions were optimized to minimize losses of P2NA due to surface absorption on glass, plastic, and rubber material, and subsequently validated. Static and dynamic diffusion cell conditions were used to study the percutaneous penetration of P2NA into freshly prepared porcine skin. The experimental settings closely resembled those of the printing industry in the 1960s/1970s in Germany where P2NA-containing solutions in dichloromethane have been used. P2NA penetrated the skin at very low levels $\left(0.02 \pm 0.01 \mu \mathrm{g} / \mathrm{cm}^{2} / \mathrm{h}\right)$ with a cumulative penetrated amount of $0.80 \pm 0.26 \mu \mathrm{g} / \mathrm{cm}^{2}$, a lag time of $6.33 \pm 2.21 \mathrm{~h}$ and under dynamic conditions. Compared to the receptor
\end{abstract}

The original version of this article was revised due to retrospective open access.

Eike Maximilian Marek and Stephan Koslitz have contributed equally to the manuscript.

Electronic supplementary material The online version of this article (doi:10.1007/s00204-017-2046-2) contains supplementary material, which is available to authorized users.

Heiko Udo Käfferlein

kaefferlein@ipa-dguv.de

1 Institute for Prevention and Occupational Medicine of the German Social Accident Insurance, Ruhr-University Bochum (IPA), Bürkle-de-la-Camp Platz 1, 44789, Bochum, Germany fluid, 10-40-fold higher concentrations were found in the skin, predominantly in the dermis and the stratum corneum. Dichloromethane acted as a penetration enhancer by increasing the cumulative penetrated amounts and the recovery of P2NA in both the receptor fluid and the skin, while shortening its lag time. However, the flux remained unaffected. Due to its accumulation in subcutaneous layers, we finally proved that P2NA is continuously released into the receptor fluid despite exposure cessation up to $160 \mathrm{~h}$. Overall, the results show that close attention has to be paid to dermal absorption of P2NA in exposed workers.

Keywords $\quad N$-Phenyl-2-naphthylamine $\cdot N$-Phenyl- $\beta$ naphthylamine $\cdot$ Franz diffusion cells $\cdot$ Percutaneous penetration $\cdot$ Skin

\section{Introduction}

$N$-Phenyl-2-naphthylamine (P2NA) is a lipophilic secondary aromatic amine and has been used in industry as an antioxidant until the 1980s to protect natural and synthetic rubbers and latexes from thermal degradation, oxidation, and flex-cracking (IARC 1982). Furthermore, P2NA was used as antioxidant in greases, lubricating oils, and transformer oils (Tolbert 1997).

P2NA was categorized in 1987 as a group 3 carcinogen (not classifiable as to its carcinogenicity to humans) by the International Agency for Research on Cancer (IARC) due to "inadequate evidence for carcinogenicity to humans" and "limited evidence for carcinogenicity to animals" (IARC 1987). Recent epidemiological studies still remain inconclusive regarding the carcinogenic risk of P2NA in humans (Sorahan 2008; Sorahan et al. 2000). However, dephenylation of P2NA to 2-naphthylamine (2NA), one 
of the most potent bladder carcinogens (IARC 2012), has been reported in rats and dogs (Weiss et al. 2013; Laham and Potvin 1983; Batten and Hathway 1977), and based on the detected amounts of 2NA in urine after oral dosage of P2NA, is also assumed in humans (Kummer and Tordoir 1975; Moore et al. 1977). Due to the metabolic conversion of P2NA to 2NA, the high carcinogenic potency of 2NA, the long latency period of urothelial cancer, and the assumed on-going use of P2NA as an antioxidant in natural and synthetic rubber industry outside western industrial nations, P2NA-associated bladder cancer at the workplace is still of relevance to the present day (Weiss et al. 2007).

The supposed main exposure routes to P2NA in industry are by inhalation (e.g., when handling powdery products) or by dermal contact (e.g., when using P2NA-containing solvents or oils) (IARC 1982). Previously, it has been reported that P2NA was unable to penetrate human skin when using Franz diffusion cells (Wellner et al. 2008), an accepted model to study the dermal absorption of potentially harmful chemicals in vitro (Bartosova and Bajgar 2012).

Here, we report the specific and ultra-sensitive quantification of P2NA in the receptor fluid of Franz diffusion cells by gas chromatography and isotope-dilution tandem-mass spectroscopy (GC-MS/MS) after percutaneous penetration through freshly prepared porcine skin. For this purpose, deuterated P2NA (P2NA- $\mathrm{d}_{5}$ ) was synthesized and used as an internal standard (ISTD). In addition, various materials used in Franz cell experiments and the composition of different receptor fluids were tested to minimize losses of P2NA due to surface absorption. A pre-validation in terms of comparing the porcine skin model with previously published data in human skin and using the primary aromatic amines aniline and $o$-toluidine showed that the results obtained by both models are fully comparable, confirming the current OECD guidelines. When applying a typical exposure scenario in the printing industry from the late 1970s where P2NA-containing solutions of dichloromethane (DCM) were applied by hand, we ultimately show that toxicologically relevant amounts of P2NA can penetrate the skin. We also report that P2NA accumulates in the subcutaneous layers of the skin. We finally show that, in spite of removing the P2NAcontaining donor solutions from the skin surface, P2NA is continuously released out of this subcutaneous depot into the receptor fluid and, for this reason, can additionally contribute to the internal body burden of exposed persons.

\section{Materials and methods}

\section{Chemicals}

P2NA (CAS 135-88-6; purity $>97 \%$ ) was purchased at TCI GmbH (Eschborn, Germany). Ethanol (EtOH), dichloromethane (DCM), $n$-hexane, acetonitrile, toluene (all of analytical grade), potassium hydroxide $(\mathrm{KOH})$, and trypsin were obtained from Merck KGaA (Darmstadt Germany). Deionized water was prepared by a Millipore Quantum Advantage system (Merck-Millipore, Darmstadt, Germany). The $0.9 \%$ solution of sodium chloride $(\mathrm{NaCl})$ was obtained by Fresenius Kabi GmbH (Bad Homburg, Germany), whereas bovine serum albumin (BSA, fraction V lyophilized powder) was purchased by VWR International (Darmstadt, Germany). Stable isotope labelled P2NA-d ${ }_{5}$ was synthesized according to Bin et al. (2014) and provided by Dr. V. Belov (Max Planck Institute for Biophysical Chemistry).

\section{Franz diffusion cells}

Diffusion cells according to Franz (Franz 1975) with six cells in parallel have been used (SES GmbH, Bechenheim, Germany). PTFE gasket rings (C. Otto Gehrckens $\mathrm{GmbH}$, Pinneberg, Germany) were used to fix the skin samples on the donor side $\left(3.14 \mathrm{~cm}^{2}\right)$. A constant physiological skin temperature $\left(32{ }^{\circ} \mathrm{C}\right)$ was ensured by heating the receptor chamber with a thermostatic circulation water bath (Thermo-Scientific, Dreieich, Germany) and using a magnetic stirrer. Depending on the tested study scenarios static and dynamic Franz cell conditions were used (see below).

\section{Preparation and use of skin samples}

Fresh porcine skin samples (sus crofa domestica) were obtained prior to scalding from the inner $(n=3)$ and outer side $(n=3)$ of the ear for each ex vivo experiment (Meyer et al. 2007). The ears were washed (cold water) and clipped, and the skin was prepared with a recommended thickness of $\sim 1 \mathrm{~mm}$ (OECD 2004) using a dermatome (Humeca, Enschede, The Netherlands). The reproducibility of the preparation and the physical integrity of the skin were tested by HE staining and bright-field microscopy. In addition, the barrier function of the porcine ear skin was compared to human skin of the inner and outer side of the hands by measuring the transepidermal water loss (TEWL, Antonov et al. 2016; Hui et al. 2012). After all percutaneous experiments, the skin samples were separated into three fractions [stratum corneum $(S C)$, epidermis, and dermis] as previously described (Turksen 2005). For this, the skin was treated with a $2.5 \%$ tryptic solution $\left(24 \mathrm{~h}, 36{ }^{\circ} \mathrm{C}\right)$. The $S C$ and dermis were separated by forceps, whereas the epidermal cells remained in suspension. The dermis was saponified ( $5 \mathrm{~mL} 1 \mathrm{~N} \mathrm{KOH}$ solution, $4 \mathrm{~h}$ ). $20 \mu \mathrm{L}$ ISTD were added to $500 \mu \mathrm{L}$ of each skin extract and the samples were prepared and analysed as described below. 


\section{Optimization of the ex vivo system}

To minimize surface absorption of P2NA, three different materials [glass, polypropylene (PP), Tygon ${ }^{\circledR}$-tubing (PTFE)], and four different receptor fluids $[0.9 \% \mathrm{NaCl}$, $5 \%$ BSA, $0.9 \% \mathrm{NaCl}+5 \% \mathrm{BSA}$, EtOH/water $(50 / 50$, $\mathrm{v} / \mathrm{v})$ ] have been tested. In addition, the stability of P2NA in 5\% BSA and EtOH/water (50/50, v/v) was tested up to $24 \mathrm{~h}$ at RT $\left(21^{\circ} \mathrm{C}\right)$ and $37{ }^{\circ} \mathrm{C}$ and in both glass and PP vessels. The potential degradation of P2NA during freezing/thawing-cycles has been studied up to 6 days. Finally, P2NA absorption has been studied for PTFE and fluororubber gasket rings, which are used to insert the skin samples in the Franz cells. For this purpose, each ring, which was treated with a P2NA-solution in a glass container $(n=6)$, was extracted by $n$-hexane and the samples were analysed as described below. All experiments were carried out using a solution of $100 \mu \mathrm{g}$ $\mathrm{P} 2 \mathrm{NA} / \mathrm{L}$ and by triplicate analyses unless otherwise noted.

\section{Calibration standards and quality control}

A stock solution of P2NA ( $1 \mathrm{~g} / \mathrm{L})$ was used to prepare two standard solutions ( 0.5 and $5 \mathrm{mg} / \mathrm{L})$, all in acetonitrile. Then, seven calibration standards $(2.5-250 \mu \mathrm{g} / \mathrm{L})$ in EtOH/water (50/50, v/v) were prepared. Similarly, a stock solution of P2NA-d $\mathrm{d}_{5}(1 \mathrm{~g} / \mathrm{L})$ was used to prepare an internal standard (ISTD) solution $(2 \mathrm{mg} / \mathrm{L})$ in acetonitrile. The calibration standards were processed as described in sample preparation. The calibration curves were plotted in terms of the ratio standard/internal standard (AUC) versus the concentration by the MassHunter Software (Agilent Technologies, Waldbronn, Germany). As no quality control material is commercially available, two P2NA solutions (10 and $30 \mu \mathrm{g} / \mathrm{L}$ ) in $0.9 \% \mathrm{NaCl}+5 \%$ BSA were prepared, similar to the calibration standards. Each analytical series contained a full set of calibration standards, one of each quality control sample and a reagent blank.

\section{Sample preparation}

Samples from the percutaneous experiments $(500 \mu \mathrm{L})$ were diluted with $4.5 \mathrm{~mL}$ of an $\mathrm{EtOH} /$ water mixture $(50 / 50$, v/v) to a final volume of $5 \mathrm{~mL}$, whereas $5 \mathrm{~mL}$ of the calibration standards were used as such. Twenty microlitre of the ISTD was added to each sample. Liquid/liquid extraction of P2NA was carried using $6 \mathrm{~mL}$ of $n$-hexane by shaking $(10 \mathrm{~min})$ and centrifugation $(10 \mathrm{~min}$ at $2100 \mathrm{~g})$. The extract was transferred to a $20-\mathrm{mL}$ screw-top vial and evaporated to $\sim 1 \mathrm{~mL}$ in a rotational vacuum concentrator (RVC 2-33 CDplus, Martin Christ GmbH, Osterode, Germany). Finally, the sample was transferred to a 1-mL screw-top vial which contained 100 $\mu \mathrm{L}$ of toluene, vortex mixed, evaporated to approximately $100 \mu \mathrm{L}$ by vacuum concentration, and transferred to a micro insert for analysis.

\section{GC-MS/MS analysis}

Analysis was carried out by gas chromatography (GC, 7890A) and triple quadrupole mass spectrometry (MS/ MS, 7000A). One microliter was injected splitless (injector temperature $300{ }^{\circ} \mathrm{C}$ ). Separation was performed on a DB5MS capillary column (phenyl-arylene polymer, $30 \mathrm{~m}$, ID $0.25 \mathrm{~mm}$, film $0.25 \mu \mathrm{m}$, J\&W Scientific). Helium 6.0 was used as the carrier gas. The temperature program was $70^{\circ} \mathrm{C}$ (3 min), $10{ }^{\circ} \mathrm{C} / \mathrm{min}$ to $120^{\circ} \mathrm{C}(1 \mathrm{~min}), 40{ }^{\circ} \mathrm{C} / \mathrm{min}$ to $280{ }^{\circ} \mathrm{C}$ (0.5 min), and $40{ }^{\circ} \mathrm{C} / \mathrm{min}$ to $320^{\circ} \mathrm{C}(3 \mathrm{~min})$. The transfer line, ion source, and quadrupole temperatures were set to 280,230 , and $150{ }^{\circ} \mathrm{C}$, respectively. The flow rate of the collision gas (nitrogen 5.0) and the quench gas (Helium 6.0) were 1.5 and $2.25 \mathrm{~mL} / \mathrm{min}$. Quantification and confirmation were carried out by multiple reaction monitoring (EI-MRM, $70 \mathrm{eV}$ ) with $m / z, 219 \rightarrow 217$ (quantifier) and $m / z, 219 \rightarrow 115$ (qualifier) for P2NA, and $\mathrm{m} / z, 224 \rightarrow 224$ (parent mass) and $224 \rightarrow 221$ for P2NA-d ${ }_{5}$.

\section{Analytical reliability}

The limit of detection (LOD) and the limit of quantitation (LOQ) of the method have been determined as $S / N$ ratio of three and nine. The intra- and inter-day imprecisions and the recovery were determined in a 5\% BSA solution at 10 and $30 \mu \mathrm{g} / \mathrm{L}(n=6$ each).

\section{Test scenario 1}

Workers in the printing industry were using up to $1 \%$ P2NA solutions in 96\% DCM and 4\% turpentine oil when refreshing rubber rolls (=protecting them from flex-cracking during use). The solutions were applied on the rubber rolls approximately four times per 8-h-shift and 5 min each. These tasks were usually carried out by hand and often without personal protection measures, such as the use of solvent-resistant gloves. Consequently, we used $0.5 \mathrm{~mL}$ of a $1 \% \mathrm{P} 2 \mathrm{NA}$ solution $\left(12 \mathrm{~g} / \mathrm{L}, 1.91 \mathrm{mg} / \mathrm{cm}^{2}\right)$ in our initial experiments. In addition, the donor solution was applied for $1 \mathrm{~h}$ on the skin only. To prevent evaporation of DCM, the donor chamber was sealed with in-house produced glass chambers. After $1 \mathrm{~h}$, the donor solution was removed, the skin in the donor cell cleaned (rinsed), and an equivalent amount of 5\% BSA solution without P2NA was added. Then, the penetration of the initially applied P2NA was further assessed up to $48 \mathrm{~h}$. The experiments were carried out using static (receptor chamber filled with $7.5 \mathrm{~mL} 5 \%$ BSA solution) and dynamic 
conditions $(7.5 \mathrm{~mL} / \mathrm{h}, 5 \%$ BSA solution $)$ in freshly prepared porcine skin. Please note that the removal of the donor solution after $1 \mathrm{~h}$ is not consistent with OECD guidelines. However, this scenario most closely resembled the workplace situations in the printing industry in the 1960s/1970s.

\section{Test scenario 2}

In line with OECD guidelines (OECD 2004), we repeated test scenario 1 without removal of the donor solution (application time $=$ observation time $=48 \mathrm{~h}$ ). Again, the experiments were carried out using static and dynamic conditions and freshly prepared porcine skin.

\section{Test scenario 3}

To study the influence of DCM/corn oil on the percutaneous absorption of P2NA, we directly compared a $5 \mathrm{mg} / \mathrm{L}$ donor solution of $\mathrm{P} 2 \mathrm{NA}$ in $0.9 \% \mathrm{NaCl} / 5 \% \mathrm{EtOH}$ with a solution in DCM/corn oil (96/4). All other experimental settings were kept constant, i.e., dynamic conditions, freshly prepared porcine skin samples, and an application time of $48 \mathrm{~h}$ were used.

\section{Skin penetration parameters}

The cumulative penetrated amount (CPA) of P2NA was calculated according to

$m_{\mathrm{P} 2 \mathrm{NA}_{n}}[\mu \mathrm{g}]=\frac{c_{\mathrm{P} 2 \mathrm{NA} t_{n}}[\mu \mathrm{g} / \mathrm{L}]}{v_{\mathrm{collt}_{n}}[\mathrm{~L}]}$

with

$$
\begin{aligned}
& m_{\text {cp-stat } t_{n}}=m_{\mathrm{P} 2 \mathrm{NA} t_{0}}+\left(m_{\mathrm{P} 2 \mathrm{NA} t_{1}}+\frac{1}{15} m_{\mathrm{P} 2 \mathrm{NA} t_{0}}\right) \\
& +\cdots+\left(m_{{\mathrm{P} 2 \mathrm{NA} t_{n}}_{n}}+\frac{1}{15} m_{\mathrm{P} 2 \mathrm{NA} t_{0}}+\cdots+\frac{1}{15} m_{{\mathrm{P} 2 \mathrm{NA} t_{n-1}}}\right) \text { (static) } \\
& m_{\text {cp-dyn } t_{n}}=m_{{\mathrm{P} 2 \mathrm{NA} t_{0}}}+m_{\mathrm{P} 2 \mathrm{NA} t_{1}}+\cdots+m_{\mathrm{P} 2 \mathrm{NA} t_{n}} \text { (dynamic) }
\end{aligned}
$$

and is presented in $\mu \mathrm{g} / \mathrm{cm}^{2}$ to guarantee that results obtained in different laboratories can be directly compared with each other. Collected samples of static experiments were immediately replaced with equal amounts of receptor solution. All penetrated levels of P2NA at each subsequent time point $\left(t_{n}\right)$ were recalculated to correctly assess the total penetrated amount of P2NA according to the ratio between the collected volume $\left(v_{\text {coll }}, 0.5 \mathrm{~mL}\right)$ and the total volume $\left(v_{\text {tot }}\right.$, $7.5 \mathrm{~mL})(=1 / 15)$. The $\%$ recovery of P2NA in the receptor fluid (Rec), the maximum flux $\left(f_{\max }, \mu \mathrm{g} / \mathrm{cm}^{2} / \mathrm{h}\right)$, and the lag time $\left(t_{\text {lag }}, \mathrm{h}\right)$ have also been determined (Harrison and Knutson 1995; Kupczewska-Dobecka et al. 2010).

\section{Results and discussion}

The use of Franz diffusion cells is a well-established ex vivo model to study drug delivery in pharmacology and extensive information is available on pharmaceuticals (for review: Bartosova and Bajgar 2012; Godin and Touitou 2007). Similarly, Franz cells have been used in toxicology to study the transdermal absorption of organophosphates (Thors et al. 2016), glycol ethers (Larese Filon et al. 1999), polybrominated flame retardants (Frederiksen et al. 2016), and primary aromatic (di) amines such as aniline, $o$-toluidine, or 4,4'-methylenedianline (Lüersen et al. 2006; Kenyon et al. 2004). Less toxicological data are available on lipophilic compounds such as benzene (Adami et al. 2006) and polycyclic aromatic hydrocarbons (Bartsch et al. 2016), possibly due to their lower solubility in water and less pronounced skin penetration characteristics when compared to hydrophilic compounds.

Here, we show that P2NA, a highly lipophilic substance and secondary aromatic amine, can penetrate the skin although a previous study failed to show its transdermal absorption (Wellner et al. 2008). More importantly, P2NA accumulated in the subcutaneous layers of the skin from where it is continuously released to the receptor fluid of the Franz cells. This leakage of P2NA, in combination with its known in vivo conversion to $2 \mathrm{NA}$, a potent bladder carcinogen in humans, can ultimately lead to toxicologically significant amounts of percutaneously absorbed P2NA.

\section{Successful standardization and pre-validation using primary aromatic amines}

Both static and dynamic Franz cells were successfully standardized along the current OECD guideline 428 (OECD 2004). A constant physiological skin temperature $\left(32 \pm 1^{\circ} \mathrm{C}\right)$ in all six Franz cells could be achieved using a thermostat $\left(37^{\circ} \mathrm{C}\right)$ for the circulating water bath and placing the porcine skin into the Franz cell 60 min prior start to achieve optimum equilibration. In case of dynamic experiments, the intra-cell $(7.55 \pm 0.05 \mathrm{~mL} / \mathrm{h}, \mathrm{SD} 2.6 \%)$ and intercell flow rates $(7.55 \pm 0.21 \mathrm{~mL} / \mathrm{h}, \mathrm{SD} 2.7 \%)$ was shown to be highly stable $(n=6)$.

The skin preparation using a dermatome was also reproducible (depth $956.87 \pm 31.97 \mathrm{~mm}, n=10$ ) and the $S C$ remained intact. The measured TEWL $(n=9)$ was similar between freshly prepared porcine ear skin $(3.91 \pm 0.67 \mathrm{~g} /$ $\mathrm{cm}^{2} / \mathrm{h}, \mathrm{SD} 17.2 \%$ ) and human skin of the inner and outer sides of the hands $\left(4.43 \pm 0.62 \mathrm{~g} / \mathrm{cm}^{2} / \mathrm{h}\right.$, SD $\left.14.0 \%\right)$, thus confirming the current OECD guidelines and previous studies showing that freshly prepared porcine ear skin can be used as a valid surrogate for human skin (OECD 2004; Bartek et al. 1972). No increase in TEWL could be observed up to $6 \mathrm{~h}$ after skin preparation (Tab. S1). 
We pre-validated our system by measuring the transdermal absorption of less lipophilic primary aromatic amines, such as aniline and $o$-toluidine where data on skin penetration have been previously published (Wellner et al. 2008). However, instead of aniline, we used aniline- $d_{5}$ to study its percutaneous absorption to avoid artefact contamination due to the omnipresence of aniline in our environment. All penetration parameters were normalized to an exposed area of $1 \mathrm{~cm}^{2}$, because the flux and the penetrated amounts of chemicals are dependent on the concentration and the exposed area (Michaels et al. 1975). Keeping in mind that we used freshly prepared porcine skin instead of frozen human skin, our data are well in line to those of Wellner and co-workers (Tab. S2).

\section{Optimizing Franz cell set-up minimizes losses of P2NA due to surface absorption}

Non-polar analytes, such as P2NA are well absorbed on glass and plastic surfaces (Unger et al. 2001; Pekas 1972). Therefore, the experimental set-up was optimized to guarantee ideal study conditions. Special emphasis was placed on alternative receptor fluids along current OECD guidelines (OECD 2004), because a P2NA solution in $0.9 \% \mathrm{NaCl}$ solution, previously used to study the ex vivo percutaneous absorption of P2NA (Wellner et al. 2008), resulted in considerable losses (recovery 30-69\%) due to surface absorption on glass, PP, and PTFE, three commonly used materials in Franz cell experiments (Tab. S3a). However, surface absorption on glass was less pronounced than on PP and PTFE. Significantly increased recoveries ( $>90 \%$, range 93-98\%) were observed for EtOH/water (50/50, v/v) and 5\% BSA in water (Tab. S3b). Consistently high recoveries of P2NA were also observed at different storage temperatures ( 21 vs. $37^{\circ} \mathrm{C}$ ), and upon testing multiple freeze/thaw cycles for both 5\% BSA solutions (Tab. S3c/d) and EtOH/water (50/50, v/v) (data not shown). With the exception of scenario 3, we chose receptor solutions containing 5\% BSA rather than 50\% ethanol, based on the additional buffering capacity of BSA and its greater physiological relevance. In addition, high levels of EtOH might further enhance the dermal penetration of $\mathrm{P} 2 \mathrm{NA}$, and thus may result in misleading interpretations on the toxicological relevance of the percutaneous absorption of P2NA.

The right choice of gasket rings has also been identified as a critical parameter in our experiments. Teflon washers made out of Teflon foam rather than solid Teflon acted like a sponge and significantly absorbed P2NA from the donor solution ( $30 \%$ of the applied dose). Consequently, fluororubber rings, an inert material, were used on the donor side to insert the porcine skin in Franz cells while further minimizing losses of P2NA.

\section{GC-MS/MS with isotope dilution allows accurate analysis of P2NA at low levels}

Only few data are currently available on the analysis of P2NA. Limits of detection (LODs) in urine and physiological $\mathrm{NaCl}$ solution were reported to be high $(\sim 50 \mu \mathrm{g} / \mathrm{L})$ due to the use of thin layer chromatography (Kummer and Tordoir 1975) or, despite the use of sensitive and specific GC-MS (Weiss and Angerer 2002), insufficient extraction, and derivatization of P2NA by diethylether and pentafluoropropionic anhydride (PFPA) (Wellner et al. 2008). In our studies, an excellent LOD $(0.1 \mu \mathrm{g} / \mathrm{L})$ and LOQ $(0.3 \mu \mathrm{g} / \mathrm{L})$ could be achieved by an efficient single liquid/liquid extraction of P2NA using $n$-hexane (extraction yield: $95 \%$ ), the use of GC-MS/MS with splitless injection, and without any further derivatization of P2NA. The use of an isotope labelled ISTD $\left(\right.$ P2NA- $\mathrm{d}_{5}$ ) significantly improved the precision, accuracy, and robustness of the developed method. For example, the calibration curve was highly linear $(2.5-2500 \mu \mathrm{g} / \mathrm{L}$, $r^{2}=0.996$ ), thus covering a wide range of potentially penetrated concentrations of P2NA. No differences in the slopes of the calibration curves could be observed between 5\% BSA and EtOH/water (50/50, v/v), which is in line with the results obtained during method development where nearly identical recoveries for P2NA were observed when both solutions were tested. Therefore, calibration standards were prepared in EtOH/water, whereas 5\% BSA was used in the ex vivo experiments (Fig. S1). None of the reagent blanks spiked with P2NA- $\mathrm{d}_{5}$ contained traces of unlabelled P2NA. Consequently, the formation of artefacts from the use of the deuterium-labelled ISTD could be excluded.

The relative recovery $(n=10)$ of P2NA at 10 and $30 \mu \mathrm{g} / \mathrm{L}$ was $95-103 \%$ and $98-102 \%$, respectively. The observed low intra-day and inter-day imprecisions $(n=9)$ at the same concentrations were $4.8-5.5 \%(10 \mu \mathrm{g} / \mathrm{L})$ and $3.2-4.1 \%$ $(30 \mu \mathrm{g} / \mathrm{L})$, and are proof that this method delivers highly reproducible results in the ex vivo experiments and at low concentrations (Fig. S1b).

\section{Workplace-similar conditions show percutaneous absorption of P2NA at low levels}

We were able to show that P2NA does penetrate the skin at very low levels when applying a donor solution of $12 \mathrm{~g}$ P2NA/L in $96 \%$ DCM and $4 \%$ corn oil for $1 \mathrm{~h}$ on the porcine skin (test scenario 1) (Fig. 1). For example, the CPA, the recovery of the applied dose, $f_{\max }$, and $t_{\text {lag }}$ when using freshly prepared skin and dynamic conditions were $0.80 \pm 0.26 \mu \mathrm{g} / \mathrm{cm}^{2}, 0.04 \pm 0.01 \%, 0.02 \pm 0.01 \mu / \mathrm{cm}^{2} / \mathrm{h}$, and $6.3 \pm 2.2 \mathrm{~h}$, respectively. Results using static conditions revealed similar penetration parameters (Table 1) showing that, in case of lipophilic chemicals such as P2NA, short 


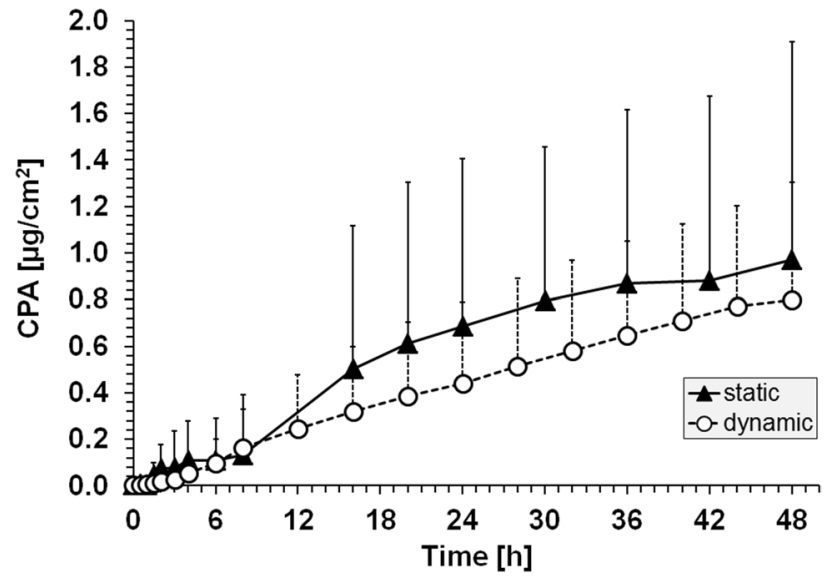

Fig. 1 Cumulative penetrated amount (CPA) of P2NA using static and dynamic Franz cell conditions after application of P2NA $(1 \mathrm{~h}$, scenario 1$)$; for the purpose of clarity, positive $\mathrm{SD}(n=6)$ are included only

Table 1 Mean and standard deviations of major skin penetration parameters of P2NA (scenario 1, $1 \mathrm{~h}$ application of P2NA, $n=6$ )

\begin{tabular}{lllll}
\hline Franz cell & $\mathrm{CPA}\left(\mu \mathrm{g} / \mathrm{cm}^{2}\right)$ & $\operatorname{Rec}(\%)$ & $f_{\max }\left(\mu \mathrm{g} / \mathrm{cm}^{2} / \mathrm{h}\right)$ & $t_{\text {lag }}(\mathrm{h})$ \\
\hline Static & $0.97 \pm 0.75$ & $0.05 \pm 0.04$ & $0.03 \pm 0.02$ & $7.90 \pm 4.09$ \\
Dynamic & $0.80 \pm 0.26$ & $0.04 \pm 0.01$ & $0.02 \pm 0.01$ & $6.33 \pm 2.21$ \\
\hline
\end{tabular}

$C P A$ cumulative penetrated amount, $R e c$ recovery, $f_{\max }$ maximum flux, $t_{\text {lag }}$ lag time

Table 2 Mean and standard deviations of major skin penetration parameters of P2NA (scenario 2, $48 \mathrm{~h}$ application, $n=6$ )

\begin{tabular}{|c|c|c|c|c|}
\hline Franz cell & $\mathrm{CPA}\left(\mu \mathrm{g} / \mathrm{cm}^{2}\right)$ & $\operatorname{Rec}(\%)$ & $f_{\max }\left(\mu \mathrm{g} / \mathrm{cm}^{2}\right.$ & $t_{\text {lag }}(\mathrm{h})$ \\
\hline Static & $0.95 \pm 0.43$ & $0.05 \pm 0.02$ & $0.03 \pm 0.01$ & $7.79 \pm 1.58$ \\
\hline Dynamic & $17.40 \pm 2.09$ & $0.91 \pm 0.42$ & $0.55 \pm 0.42$ & $12.23 \pm 1.09$ \\
\hline
\end{tabular}

$C P A$ cumulative penetrated amount, $R e c$ recovery, $f_{\max }$ maximum flux, $t_{\text {lag }}$ lag time

application times and slow penetration characteristics allow the use of simpler static conditions to study percutaneous absorption, although saturation effects in the receptor fluid cannot be ruled out completely. Increased lag times and low recoveries of $\mathrm{P} 2 \mathrm{NA}$ in the receptor fluid require, as already outlined in the OECD guideline (OECD 2004), an extended observation time of at least $48 \mathrm{~h}$ and an optimized receptor fluid to detect percutaneously absorbed amounts of lipophilic chemicals such as P2NA. When comparing aniline and P2NA at similar concentrations (aniline: $3 \mathrm{~g} / \mathrm{L}$, Tab. S1; P2NA: $12 \mathrm{~g} / \mathrm{L}$, this study, the same order of magnitude), the observed flux is about 1000 times lower for P2NA. Overall, our results show that the percutaneous absorption of P2NA

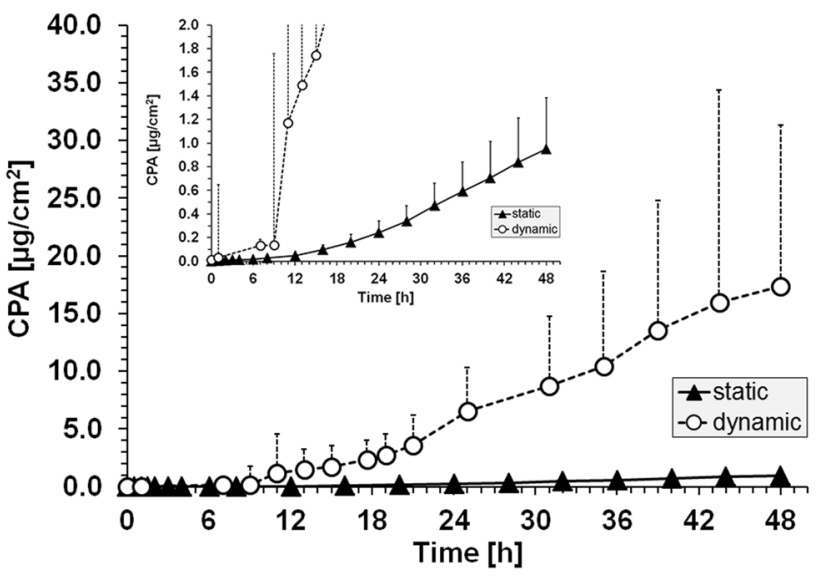

Fig. 2 Cumulative penetrated amount (CPA) of P2NA using static and dynamic Franz cell conditions after application of P2NA (48 h, scenario 2); the inlet shows the identical diagram with a different $y$-axis intercept to make the SD for the static penetration curve visible; for the purpose of clarity, positive $\operatorname{SD}(n=6)$ are included only

can be efficiently studied in Franz cells using freshly prepared porcine skin.

\section{Percutaneous absorption of P2NA is confirmed when following OECD guidelines}

When we extended the application time to $48 \mathrm{~h}$ in compliance with OECD guidelines (scenario 2), we confirmed the percutaneous absorption of P2NA (Fig. 2; Table 2). Dynamic conditions revealed higher penetration parameters compared to static conditions (CPA: $17.40 \pm 2.09$ vs. $0.95 \pm 0.43$; $f_{\max }: 0.55 \pm 0.42$ vs. $0.03 \pm 0.01 ; t_{\text {lag }}: 12.23 \pm 1.09$ vs. $11.64 \pm 5.02$; Rec: $0.91 \pm 0.43$ vs. $0.05 \pm 0.02$ ), most likely based on a constant exchange of the receptor fluid beneath the skin. Therefore, no rate-limiting effects, such as saturation of P2NA in the receptor fluid can occur (Bronaugh and Stewart 1985). Similar differences were observed when comparing the guideline-specific results to those of the workplace-similar results under dynamic conditions. Higher penetration parameters in the guideline-specific results can be explained by the longer application time of the substance ( 48 vs. $1 \mathrm{~h}$ ). Interestingly, this difference could not be observed under static conditions, possibly due to saturation effects at the skin/receptor fluid interface and despite magnetic stirring (Díez-Sales et al. 1991). There, nearly identical results were observed for all penetration parameters between guidelinespecific and workplace-similar results (Tables 1,2) with the exception of $t_{\text {lag }}$ which was slightly higher when following the OECD guideline ( $t_{\operatorname{lag}} 11.6$ vs. $7.9 \mathrm{~h}$ ). This difference is most likely a mathematical artefact based on the fact that $t_{\text {lag }}$ is calculated by extrapolating the slope of the penetration curve at $f_{\max }$ rather than presenting a true difference of $t_{\text {lag }}$ between both experiments. 


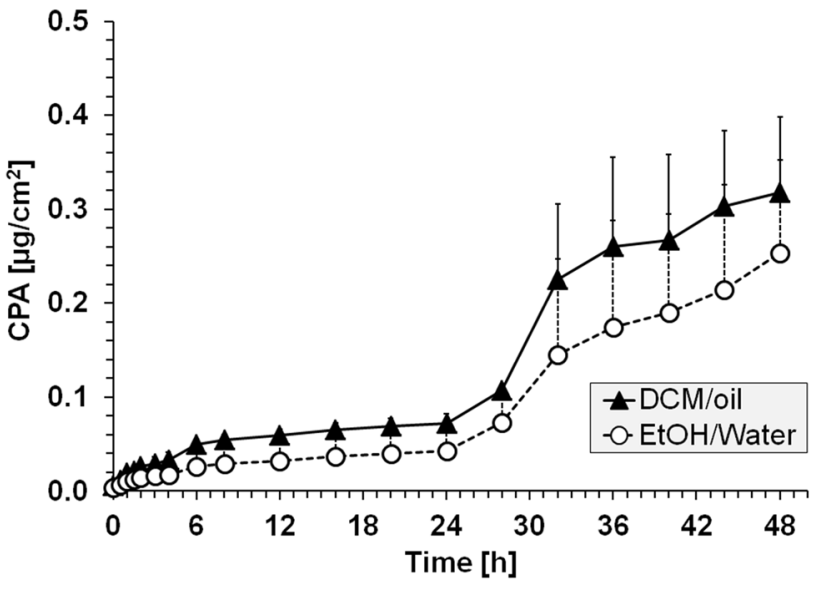

Fig. 3 Cumulative penetrated amount (CPA) of P2NA in intact skin using dynamic Franz cell conditions after application of a $5 \mathrm{mg} / \mathrm{L}$ solution of P2NA (48 h, scenario 3) in $0.9 \% \mathrm{NaCl} / 5 \%$ ethanol/water and $96 \% \mathrm{DCM} / 4 \%$ corn oil; for the purpose of clarity, positive SD $(n=6)$ are included only

Table 3 Mean and standard deviations of major skin penetration parameters after application of P2NA $(5 \mathrm{mg} / \mathrm{L})$ in $0.9 \% \mathrm{NaCl} / 5 \%$ EtOH and $96 \%$ DCM/4\% corn oil, an application time of $48 \mathrm{~h}$, and under dynamic conditions (scenario $3, n=6$ )

\begin{tabular}{lllll}
\hline Donor & $\mathrm{CPA}\left(\mu \mathrm{g} / \mathrm{cm}^{2}\right)$ & $\operatorname{Rec}(\%)$ & $f_{\max }\left(\mu \mathrm{g} / \mathrm{cm}^{2} / \mathrm{h}\right)$ & $t_{\mathrm{lag}}(\mathrm{h})$ \\
\hline $\begin{array}{l}0.9 \% \mathrm{NaCl} / \\
5 \% \mathrm{EtOH}\end{array}$ & $0.25 \pm 0.10$ & $31.87 \pm 12.57$ & $0.01 \pm 0.01$ & $21.10 \pm 1.83$ \\
& & & & \\
$\begin{array}{c}96 \% \mathrm{DCM} / \\
4 \% \text { corn oil }\end{array}$ & $0.32 \pm 0.08$ & $56.23 \pm 35.19$ & $0.02 \pm 0.01$ & $16.77 \pm 7.13$ \\
& & & &
\end{tabular}

$C P A$ cumulative penetrated amount, $R e c$ recovery, $f_{\max }$ maximum flux, $t_{\text {lag }}$ lag time

The results of both scenarios 1 and 2 show that more reliable results can be achieved using dynamic conditions, possibly based on the improved agreement with physiological conditions (i.e., simulating P2NA removal via blood flow) and its greater stability and robustness. In particular, saturation effects can be prevented by using dynamic conditions, which in turn, makes dynamic conditions the preferred option to study the percutaneous absorption of lipophilic chemicals, specifically at increased application times ( $\geq 48 \mathrm{~h}$ ).

\section{Percutaneous absorption is enhanced by dichloromethane}

To directly study the influence of DCM/corn oil on the penetration of P2NA (scenario 3), it was necessary to use a lower concentrated and more aqueous solution of P2NA ( $5 \mathrm{mg} / \mathrm{L}$, $0.9 \% \mathrm{NaCl}+5 \% \mathrm{EtOH}$ as solubilizer) as a reference. The results were directly compared to a $5 \mathrm{mg} / \mathrm{L}$ solution of P2NA in $96 \%$ DCM and 4\% corn oil. Based on the aforementioned results, dynamic conditions and an application time of $48 \mathrm{~h}$ were chosen. A slightly increased percutaneous absorption was observed in the presence of DCM/corn oil, suggesting that DCM acts as penetration enhancer and facilitates the percutaneous absorption of P2NA (Fig. 3). However, an approximately 1.5 -fold increase in CPA was observed after $48 \mathrm{~h}$ only $\left(0.25\right.$ to $0.32 \mu \mathrm{g} / \mathrm{cm}^{2}$ ) (Table 3 ), whereas the penetration-enhancing properties must be considered negligible at shorter observation times. The solvent enhancing effect was confirmed based on slightly higher recovery rates and a shortening in $t_{\text {lag }}$. Nevertheless, $f_{\max }$ remained unchanged. The observed minor DCM-enhancing effects are possibly due to a "residual solvent effect" $(5 \% \mathrm{EtOH}$ as solubilizer in the reference solution), which decreases the differences between the P2NA penetration curves in DCM/oil and 0.9\% $\mathrm{NaCl}$ in EtOH/water. However, due to the poor solubility of $\mathrm{P} 2 \mathrm{NA}$ in $100 \%$ water, no donor solutions without EtOH (true negative control) could be tested.

\section{P2NA accumulates in subcutaneous layers of the skin}

International guidelines (COLIPA 1997; EPA 1999; SCCNEFP 1999; OECD 2004) with the exception of ECETOC (1993) all recommend the analysis and interpretation of the absorbed amounts in different cutaneous layers including the $S C$, epidermis, and dermis when studying the percutaneous absorption of lipophilic chemicals. However, only OECD (2004) and EPA (1999) recommend to include the SC in the interpretation of the results, whereas COLIPA (1997) and SCCNEFP (1999) do not, because they both consider chemicals in the $S C$ as not bioavailable. Consequently, we analysed the $S C$, epidermis, and dermis of all skin samples at the time point of $48 \mathrm{~h}$.

A direct comparison of the amounts of P2NA in the receptor fluids to those in the skin indicated an approximately 10-40-fold higher levels in the skin at $48 \mathrm{~h}$ (Tab. S4). Despite varying results, most of the percutaneously absorbed P2NA is observed in the dermis, followed by the $S C$ and the epidermal fraction (Table 4). As expected, higher \%-recoveries of P2NA were observed in the skin at $48 \mathrm{~h}$ compared to $1 \mathrm{~h}$ application times, and under both static $(5.11 \pm 3.53$ vs. $0.93 \pm 0.45)$ and dynamic conditions $(5.53 \pm 2.06$ vs. $3.51 \pm 1.78)$. Similarly, significantly increased penetrated amounts were observed in the skin samples derived from the experiments at higher concentrations (at $12 \mathrm{~g} / \mathrm{L}: \sim 105 \mu \mathrm{g}$ $\mathrm{P} 2 \mathrm{NA} / \mathrm{cm}^{2}$ when adding up the amounts of P2NA in $S C$, epidermis, and dermis) compared to lower concentrations (at $5 \mathrm{mg} / \mathrm{L}: \sim 13 \mu \mathrm{g} / \mathrm{cm}^{2}$ ). Conversely, the \%-recoveries were significantly decreased at higher concentrations $(12 \mathrm{~g} / \mathrm{L}$ : $5.53 \pm 2.06 ; 5 \mathrm{mg} / \mathrm{L}: 16.08 \pm 13.75$ ), because P2NA is less prone to reside in the skin. The results suggest a non-linear relationship between the applied concentrations and the 
Table 4 P2NA in various cutaneous layers of intact skin in terms of the penetrated amounts $\left(\mu \mathrm{g} / \mathrm{cm}^{2}\right)$ and the recovery $(\%)$ at the end of all experiments (time point $48 \mathrm{~h}$ )

\begin{tabular}{|c|c|c|c|c|}
\hline Franz cell & $\mathrm{PA}_{\mathrm{sc}}\left(\mu \mathrm{g} / \mathrm{cm}^{2}\right)$ & $\mathrm{PA}_{\text {epi }}\left(\mu \mathrm{g} / \mathrm{cm}^{2}\right)$ & $\mathrm{PA}_{\text {derm }}\left(\mu \mathrm{g} / \mathrm{cm}^{2}\right)$ & $\operatorname{Rec}(\%)$ \\
\hline \multicolumn{5}{|c|}{ Scenario 1: $12 \mathrm{~g} / \mathrm{L}$ P2NA ${ }^{\text {a }}$; application $1 \mathrm{~h}$} \\
\hline Static & $9.52 \pm 5.74$ & $1.02 \pm 0.35$ & $7.20 \pm 2.53$ & $0.93 \pm 0.45$ \\
\hline Dynamic & $7.37 \pm 5.22$ & $24.92 \pm 13.56$ & $34.68 \pm 15.19$ & $3.51 \pm 1.78$ \\
\hline \multicolumn{5}{|c|}{ Scenario 2: $12 \mathrm{~g} / \mathrm{L}$ P2NA ${ }^{\mathrm{a}}$; application $48 \mathrm{~h}$} \\
\hline Static & $38.18 \pm 35.29$ & $12.23 \pm 8.21$ & $47.23 \pm 23.86$ & $5.11 \pm 3.53$ \\
\hline Dynamic & $32.60 \pm 12.53$ & $29.62 \pm 14.82$ & $43.46 \pm 12.02$ & $5.53 \pm 2.06$ \\
\hline \multicolumn{5}{|c|}{ Scenario 3: $5 \mathrm{mg} / \mathrm{L}$ P2NA $\mathrm{N}^{\mathrm{a}, \mathrm{b}}$; application $48 \mathrm{~h}$} \\
\hline Dynamic $^{\mathrm{a}}$ & $1.40 \pm 1.10$ & $3.66 \pm 4.23$ & $7.81 \pm 4.04$ & $16.08 \pm 13.75$ \\
\hline Dynamic $^{b}$ & $1.33 \pm 0.77$ & $0.82 \pm 0.56$ & $5.70 \pm 4.04$ & $9.81 \pm 11.72$ \\
\hline
\end{tabular}

$P A_{s c}, P A_{e p i}, P A_{\text {derm }}$ penetrated amount in stratum corneum, epidermis, and dermis, Rec recovery

${ }^{\mathrm{a}}$ In $96 \% \mathrm{DCM} / 4 \%$ oil

${ }^{\mathrm{b}}$ In $0.9 \% \mathrm{NaCl} / 5 \% \mathrm{EtOH}$ penetration parameters for lipophilic substances, whereas a linear relationship has been observed when using less lipophilic primary aromatic amines such as aniline (Wellner et al. 2008).

At identical concentrations ( $5 \mathrm{mg} / \mathrm{L})$, higher amounts of P2NA were observed in the skin and the receptor fluid when using a solution of $96 \% \mathrm{DCM} / 4 \%$ oil compared to $0.9 \% \mathrm{NaCl}$ in $5 \% \mathrm{EtOH} /$ water (Tables 3, 4). The same is true for the \%-recoveries. For example, the \%-recovery in skin $(9.8 \%)$ and the receptor fluid (31.9\%) is lower in case of the $5 \mathrm{mg} / \mathrm{L}$ solution of P2NA in $0.9 \% \mathrm{NaCl} / 5 \% \mathrm{EtOH}$ compared to the solution in $96 \%$ DCM/4\% oil (16.1 and $56.2 \%$, respectively). These results, despite $\operatorname{similar} f_{\max }$ in both experiments $\left(\sim 0.01-0.02 \mu \mathrm{g} / \mathrm{cm}^{2} / \mathrm{h}\right)$, further demonstrate a penetration-enhancing effect of DCM. This effect is most likely based on the high skin permeability of DCM itself rather than its skin-damaging potential. Although an irritating effect of DCM on the skin (in particular on SC) cannot be completely ruled out, our results show that such a damage is unlikely due to a similar shape of the penetration curves with and without DCM (Fig. 3). In addition, the amount of P2NA in the $S C$ was similar with and without DCM (Table 4). Consequently, we assume that DCM "pushes P2NA through the intact skin" based on its own high skin permeability and does not allow P2NA to interact with cutaneous structures, an assumption which is further supported by the observed decreased $t_{\text {lag }}$ in DCM/oil compared to $\mathrm{EtOH} /$ water.

\section{The combination of percutaneous absorption and accumulation in skin can result in toxicologically significant amounts of P2NA}

Our results clearly show that the most reliable results for the percutaneous penetration of P2NA are observed when a combination of dynamic Franz cells and freshly prepared porcine skin is used. The CPA, recovery, and $f_{\max }$ in

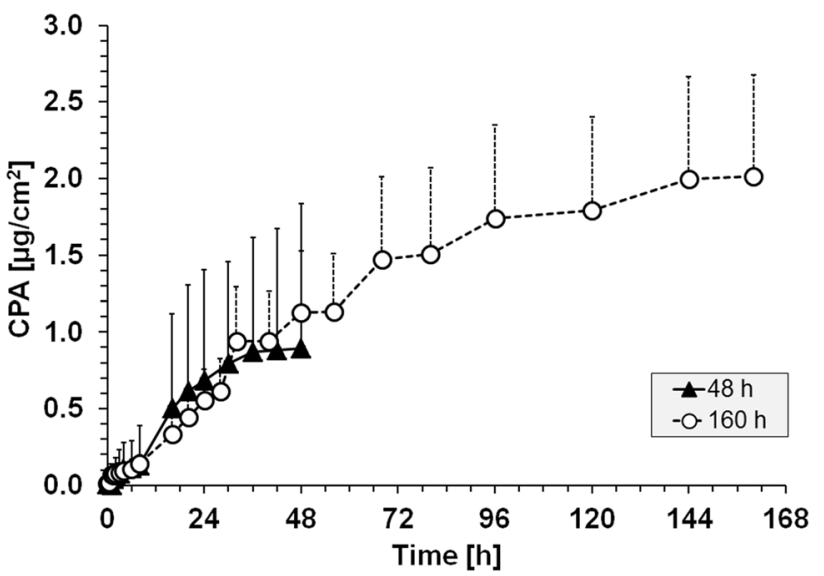

Fig. 4 Percutaneous absorption of P2NA (12 g/L in 96\% DCM/4\% corn oil) up to $160 \mathrm{~h}$ under static conditions, an application time of $1 \mathrm{~h}$, and compared to the results obtained in the initial experiment (scenario 1) with an observation time of $48 \mathrm{~h}$ only

scenario 1, which most closely resembles the former workplace situation in the $1960 \mathrm{~s} / 1970 \mathrm{~s}$ in the printing industry $(c=12 \mathrm{~g} / \mathrm{L}, t=1 \mathrm{~h})$ were $0.80 \pm 0.26 \mu \mathrm{g} / \mathrm{cm}^{2}, 0.04 \pm 0.01 \%$, and $0.02 \pm 0.01 \mu \mathrm{g} / \mathrm{cm}^{2} / \mathrm{h}$, respectively. Conversely, 1000fold higher $f_{\max }$ values $\left(>20 \mu \mathrm{g} / \mathrm{cm}^{2} / \mathrm{h}\right)$ could be found for primary aromatic amines, such as aniline and $o$-toluidine at similarly high concentrations ( $\geq 3 \mathrm{~g} / \mathrm{L}$, Wellner et al. 2008). Therefore, dermal exposure of P2NA appears to be very low, and at first glance, suggests an only minor contribution to the total internal body burden (and consequently bladder cancer risk) of workers, despite its conversion to highly carcinogenic 2NA in vivo.

However, the results of scenario 1 also show a constant increase in the cumulative penetrated amount of P2NA up to $48 \mathrm{~h}$, although the donor solution was removed after $1 \mathrm{~h}$ (Fig. 1). In combination with the observed accumulation in skin, we assumed that P2NA is constantly released from the subcutaneous layers of the skin. Therefore, we repeated 
the experiment and extended the observation time up to $160 \mathrm{~h}$. Again, the results show a clear and constant increase in the CPA of P2NA (Fig. 4) despite the removal of the P2NA-containing donor solution after $1 \mathrm{~h}$. The results further strengthen the assumption that P2NA is continuously released from subcutaneous skin layers, and consequently further contributes to the internal body burden of P2NA in workers despite exposure cessation.

Overall, our results clearly show that close attention must be paid to dermal absorption of P2NA in risk assessment of formerly exposed workers and specific exposure circumstances, such as the presence or absence of penetration enhancers and the potential accumulation of a substance in the skin, which needs to be addressed. Furthermore, nonocclusive exposure circumstances including the rapid evaporation of DCM must be taken into account, which may additionally influence dermal uptake of P2NA at workplaces.

Acknowledgements This research was core-funded by the German Social Accident Insurance Institution of the Energy, Textile, Electrical and Media Products Sector (BG ETEM) as part of their intramural research program. The contents and the opinions of this article are solely the responsibility of the authors and do not necessarily represent the official views of the BG ETEM. Many thanks are due to M. Lieverz for technical assistance and Dr. R. Marchan for editorial review prior submission.

Open Access This article is distributed under the terms of the Creative Commons Attribution 4.0 International License (http://creativecommons.org/licenses/by/4.0/), which permits unrestricted use, distribution, and reproduction in any medium, provided you give appropriate credit to the original author(s) and the source, provide a link to the Creative Commons license, and indicate if changes were made.

\section{References}

Adami G, Larese F, Venier M, Barbieri P, Lo Coco F, Reisenhofer E (2006) Penetration of benzene, toluene and xylenes contained in gasolines through human abdominal skin in vitro. Toxicol Vitro 20:1321-1330

Antonov D, Schliemann S, Elsner P (2016) Methods for the assessment of barrier function. Curr Probl Dermatol 49:61-70

Bartek MJ, LaBudde JA, Maibach HI (1972) Skin permeability in vivo: comparison in rat, rabbit, pig, and man. J Invest Dermatol 58:114-123

Bartosova L, Bajgar J (2012) Transdermal drug delivery in vitro using diffusion cells. Curr Med Chem 19:4671-4677

Bartsch N, Heidler J, Vieth B, Hutzler C, Luch A (2016) Skin permeation of polycyclic aromatic hydrocarbons: a solvent-based in vitro approach to assess dermal exposures against benzo[a]pyrene and dibenzopyrenes. J Occup Environ Hyg 13:969-979

Batten PL, Hathway DE (1977) Dephenylation of $N$-phenyl-2-naphthylamine in dogs and its possible oncogenic implications. Br J Cancer 35:342-346

Bin JG, Lee SJ, Lee BS, Yu JH; Yu YJ, Park JS (2014) Compound for organic light emitting diode, patent KR20140073635 (A), June 17 th 2014

Bronaugh RL, Stewart RF (1985) Methods for in vitro percutaneous absorption studies IV: the flow-through diffusion cell. J Pharm Sci 74:64-67
COLIPA (1997) Guidelines for percutaneous absorption/penetration, European Cosmetic, Toiletry and Perfumers Association

Díez-Sales O, Copoví A, Casabó VG, Herráez M (1991) A modelistic approach showing the importance of the stagnant aqueous layers in in vitro diffusion studies, and in vitro-in vivo correlations. Int J Pharm 77:1-11

ECETOC (1993) Monograph Report No. 20 Percutaneous absorption, European Centre for Ecotoxicology and Toxicology of Chemicals

EPA (1999) Proposed rule for in vitro dermal absorption rate testing of certain chemicals of interest to occupational safety and health administration. Fed Reg 64(110):31073-31090

Franz TJ (1975) Percutaneous absorption on the relevance of in vitro data. J Invest Dermatol 64:190-195

Frederiksen M, Vorkamp K, Jensen NM, Sørensen JA, Knudsen LE, Sørensen LS, Webster TF, Nielsen JB (2016) Dermal uptake and percutaneous penetration of ten flame retardants in a human skin ex vivo model. Chemosphere 162:308-314

Godin B, Touitou E (2007) Transdermal skin delivery: predictions for humans from in vivo, ex vivo and animal models. Adv Drug Deliv Rev 59:1152-1161

Harrison DJ, Knutson K (1995) Accurate determination of skin flux from flow-through diffusion cell data. Pharm Res 12:2003-2011

Hui X, Elkeeb R, Chan H, Maibach HI (2012) Ability to estimate relative percutaneous penetration via a surrogate maker-trans epidermal water loss? Skin Res Technol 18:108-113

IARC (1982) The Rubber Industry. IARC Monogr Eval Carcinogen Risks Hum 28(51-52):269

IARC (1987) N-Phenyl-2-naphthylamine. IARC Monogr Eval Carcinogen Risk Hum Suppl 7:318

IARC (2012) Chemical agents and related occupations. IARC Monogr Eval Carcinogen Risk Hum 100F:83-92

Kenyon SH, Bhattacharyya J, Benson CJ, Carmichael PL (2004) Percutaneous penetration and genotoxicity of 4,4'-methylenedianiline through rat and human skin in vitro. Toxicology 196:65-75

Kummer R, Tordoir WF (1975) Phenyl- $\beta$-naphthylamine (PBNA), another carcinogenic agent? T Soc Geneesk 53:415-419

Kupczewska-Dobecka M, Jakubowski M, Czerczak S (2010) Calculating the dermal flux of chemicals with OELs based on their molecular structure: an attempt to assign the skin notation. Environ Toxicol Pharmacol 30:95-102

Laham S, Potvin M (1983) Biological conversion of $N$-phenyl-2-naphthylamine to 2-naphthylamine in the Sprague-Dawley rat. Drug Chem Toxicol 6:295-309

Larese Filon F, Fiorito A, Adami G, Barbieri P, Coceani N, Bussani R, Reisenhofer E (1999) Skin absorption in vitro of glycol ethers. Int Arch Occup Environ Health 72:480-484

Lüersen L, Wellner T, Koch HM, Angerer J, Drexler H, Korinth G (2006) Penetration of $\beta$-naphthylamine and $o$-toluidine through human skin in vitro. Arch Toxicol 80:644-646

Meyer W, Kasza J, Zschemisch NH, Godynicki S, Seeger J (2007) Observations on the actual structural conditions in the stratum superficiale dermidis of porcine ear skin, with special reference to ist use as model for human skin. Ann Anat 189:143-156

Michaels AS, Chandrasekaran SK, Shaw JE (1975) Drug permeation through human skin: theory and in vitro experimental measurement. AIChE J 21:985-996

Moore RM, Woolf BS, Stein HP, Thomas AW, Finklea JF (1977) Metabolic precursors of a known human carcinogen. Science 195:344

OECD (2004) Guidance document for the conduct of skin absorption studies. Environment Directorate. OECD Environmental Health and Safety Publications Series on Testing and Assessment, No. 28

Pekas JC (1972) Retention of lipophilic compounds on laboratory tubing. Toxicol Appl Pharmacol 21:586-588

SCCNEFP (1999) Opinion concerning basic criteria for the in vitro assessment of percutaneous absorption of cosmetic ingredients. 
Scientific Committee on Cosmetic Products and Non-Food Products intended for Consumers, European Commission

Sorahan T (2008) Bladder cancer risks in workers manufacturing chemicals for the rubber industry. Occup Med 58:496-501

Sorahan T, Hamilton L, Jackson JR (2000) A further cohort study of workers employed at a factory manufacturing chemicals for the rubber industry, with special reference to the chemicals 2-mercaptobenzothiazole (MBT), aniline, phenyl- $\beta$-naphthylamine and $o$-toluidine. Occup Environ Med 57:106-115

Thors L, Koch B, Koch M, Hägglund L, Bucht A (2016) In vitro human skin penetration model for organophosphorus compounds with different physicochemical properties. Toxicol In Vitro 32:198-204

Tolbert PE (1997) Oils and cancer. Cancer Causes Control 8:386-405

Turksen K (2005) Epidermal cells. In: Methods and protocols. Methods in molecular biology. Humana Press Inc, Totowa, p 289

Unger JK, Kuehlein G, Schroers A, Gerlach JC, Rossaint R (2001) Adsorption of xenobiotics to plastic tubing incorporated into dynamic in vitro systems used in pharmacological researchlimits and progress. Biomaterials 22:2031-2037

Weiss T, Angerer J (2002) Simultaneous determination of various aromatic amines and metabolites of aromatic nitro compounds in urine for low level exposure using gas chromatography-mass spectrometry. J Chromatogr B 778:179-192

Weiss T, Brüning T, Bolt HM (2007) Dephenylation of the rubber chemical $N$-phenyl-2-naphthylamine to carcinogenic 2-naphthylamine: a classical problem revisited. Crit Rev Toxicol 37:553-566

Weiss T, Bolt HM, Schlüter G, Koslitz S, Taeger D, Welge P, Brüning T (2013) Metabolic dephenylation of the rubber antioxidant $\mathrm{N}$-phenyl-2-naphthylamine to carcinogenic 2-naphthylamine in rats. Arch Toxicol 87:1265-1272

Wellner T, Lüersen L, Schaller KH, Angerer J, Drexler H, Korinth G (2008) Percutaneous absorption of aromatic amines-a contribution for human health risk assessment. Food Chem Toxicol 46:1960-1968 